\title{
Role of residue 87 in substrate selectivity and regioselectivity of drug-metabolizing cytochrome P450 CYP102A1 M11
}

\author{
Eduardo Vottero • Vanina Rea · Jeroen Lastdrager • \\ Maarten Honing • Nico P. E. Vermeulen • \\ Jan N. M. Commandeur
}

Received: 5 January 2011 / Accepted: 26 April 2011/Published online: 13 May 2011

(C) The Author(s) 2011. This article is published with open access at Springerlink.com

\begin{abstract}
CYP102A1, originating from Bacillus megaterium, is a highly active enzyme which has attracted much attention because of its potential applicability as a biocatalyst for oxidative reactions. Previously we developed drug-metabolizing mutant CYP102A1 M11 by a combination of site-directed and random mutagenesis. CYP102A1 M11 contains eight mutations, when compared with wild-type CYP102A1, and is able to produce humanrelevant metabolites of several pharmaceuticals. In this study, active-site residue 87 of drug-metabolizing mutant CYP102A1 M11 was mutated to all possible natural amino acids to investigate its role in substrate selectivity and regioselectivity. With alkoxyresorufins as substrates, large differences in substrate selectivities and coupling efficiencies were found, dependent on the nature of residue 87. For all combinations of alkoxyresorufins and mutants, extremely fast rates of NADPH oxidation were observed (up to $6,000 \mathrm{~min}^{-1}$ ). However, the coupling efficiencies were extremely low: even for the substrates showing the highest rates of O-dealkylation, coupling efficiencies were lower
\end{abstract}

E. Vottero and V. Rea contributed equally to this work.

E. Vottero - V. Rea - J. Lastdrager - N. P. E. Vermeulen

J. N. M. Commandeur ( $\square)$

Section of Molecular Toxicology,

Faculty of Sciences,

Leiden/Amsterdam Center for Drug Research (LACDR),

Vrije Universiteit,

De Boelelaan 1083,

1081 HV Amsterdam, The Netherlands

e-mail: j.n.m.commandeur@vu.nl

\section{Honing}

Department of Medicinal Chemistry,

Schering-Plough Research Institute,

P.O. Box 20, 5340 BH Oss, The Netherlands than $1 \%$. With testosterone as the substrate, all mutants were able to produce three hydroxytestosterone metabolites, although with different activities and with remarkably different product ratios. The results show that the nature of the amino acid at position 87 has a strong effect on activity and regioselectivity in the drug-metabolizing mutant CYP102A1 M11. Because of the wide substrate selectivity of CYP102A1 M11 when compared with wild-type CYP102A1, this panel of mutants will be useful both as biocatalysts for metabolite production and as model proteins for mechanistic studies on the function of $\mathrm{P} 450 \mathrm{~s}$ in general.

Keywords Drug-metabolizing cytochrome CYP102A1 . Site-directed mutagenesis · Position 87 - Alkoxyresorufins · Testosterone

\section{Introduction}

Cytochrome P450 BM3 (CYP102A1; EC 1.14.14.1) from Bacillus megaterium is a soluble protein that catalyzes the hydroxylation and epoxidation of several long-chain fatty acids. CYP102A1 contains a heme and reductase domain fused in a single polypeptide, which might explain why this enzyme has the highest activity ever reported for a P450 $[1,2]$. By using site-directed and/or random mutagenesis, several research groups have succeeded in broadening the substrate selectivity of this enzyme with the objective to create highly efficient biocatalysts to be used for several biotechnological applications [3-5]. In parallel, many mechanistic studies have been devoted to rationalizing the roles of various active-site residues in substrate selectivity and in the catalytic cycle [1]. One of the most studied active-site residues is Phe87, which is close to the heme 
according to the crystal structures of CYP102A1 [1]. In the substrate-free crystal, this residue lies perpendicular to the heme at the end of the substrate-access channel. Upon binding of substrate, the orientation of Phe87 changes to parallel to the plane of the heme, thereby influencing the orientation of the substrate relative to the catalytic center [6]. Many studies have been performed in which Phe87 of wild-type CYP102A1 or mutants of CYP102A1 has been mutated to other amino acids, as summarized in Table 1. Typically, in these studies one to maximally four different mutations at position 87 were compared. In most cases, Phe87 was mutated to amino acids with small nonpolar side chains (Gly, Ala, Leu, Ile, Val), whereas only two uncharged polar amino acids (Ser, Tyr) were evaluated. Dependent on the substrate tested and the enzyme template, the type of mutation of Phe 87 has differential effects on catalytic properties of $\mathrm{P} 450$ (Table 1), which are rationalized by the changes in active-site volume, thereby restricting or improving access to the reactive oxygen species at the heme center [7-21].

Table 1 Effect of mutation of residue 87 on regioselectivity/stereoselectivity of wild-type and mutant CYP102A1

\begin{tabular}{|c|c|c|c|c|}
\hline Mutation & Template & Substrate & Effect & References \\
\hline \multirow[t]{2}{*}{ F87G } & Wild type & Lauric acid & Less active; biphasic kinetics; changed regioselectivity & {$[9,19]$} \\
\hline & Wild type & Propylbenzene, chlorostyrene & More active; changed regioselectivity/stereoselectivity & [11] \\
\hline \multirow[t]{15}{*}{ F87A } & Wild type & Lauric acid, palmitic acid & Less active; changed regioselectivity & {$[7,18,19]$} \\
\hline & Wild type & Farnesol & More active; changed regioselectivity & [18] \\
\hline & Wild type & Fluoranthene, phenanthrene, pyrene & More active; changed regioselectivity & {$[10]$} \\
\hline & Wild type & Propylbenzene & Changed regioselectivity & [11] \\
\hline & Wild type & Chlorostyrene & Less active; higher enantioselectivity & [11] \\
\hline & Wild type & $(+)$-Valencene & Changed regioselectivity & {$[21]$} \\
\hline & Wild type & Resveratrol & Less active & {$[20]$} \\
\hline & A328I & $(+)$-Valencene & More active & {$[21]$} \\
\hline & $\mathrm{A} 328 \mathrm{~F}$ & Limonene & More active & {$[21]$} \\
\hline & $\mathrm{R} 47 \mathrm{~L} / \mathrm{Y} 51 \mathrm{~F}$ & $(+)$-Valencene & Changed regioselectivity & [14] \\
\hline & $\mathrm{R} 47 \mathrm{~L} / \mathrm{Y} 51 \mathrm{~F}$ & Resveratrol & Less active & {$[20]$} \\
\hline & $9-10 \mathrm{~A}$ & Phenyl acetic acid esters, buspirone & More active; higher enantioselectivity & [16] \\
\hline & $\mathrm{C}(73-78)$ & Lauric acid, palmitic acid, farnesol & Less active & [18] \\
\hline & $\mathrm{C}(75-80)$ & Lauric acid, palmitic acid, farnesol & Less active; unchanged regioselectivity & [18] \\
\hline & $\mathrm{C}(78-82)$ & Lauric acid, palmitic acid, farnesol & Less active & {$[18]$} \\
\hline \multirow[t]{6}{*}{ F87V } & Wild type & Lauric acid & Less active; changed regioselectivity & [19] \\
\hline & Wild type & Arachidonic acid, eicopentenoic acid & Less active; changed regioselectivity & {$[8]$} \\
\hline & Wild type & Aromatic and phenolic compound & More active; changed regioselectivity & {$[15]$} \\
\hline & Wild type, A328L & Geranyl acetone & More active; changed regioselectivity & {$[21]$} \\
\hline & A328I, A328V & $(+)$-Valencene & More active; changed regioselectivity & {$[21]$} \\
\hline & R47L; R47L/L188Q & Benzyloxyresorufin and pentoxyresorufin & More active & [13] \\
\hline \multirow[t]{7}{*}{ F87L } & Wild type & Lauric acid & Less active; changed regioselectivity & {$[18]$} \\
\hline & Wild type & Geranyl acetone & Less active; changed regioselectivity & {$[21]$} \\
\hline & A328I & $(+)$-Valencene & More active & {$[21]$} \\
\hline & A328V & Limonene, geranyl acetone & Less active & {$[21]$} \\
\hline & $\mathrm{C}(73-78) ; \mathrm{C}(75-80)$ & Lauric acid, palmitic, acid, farnesol & Less active & {$[18]$} \\
\hline & $\mathrm{C}(78-82)$ & Lauric acid, palmitic acid & Less active & {$[18]$} \\
\hline & $\mathrm{C}(78-82)$ & Farnesol & More active; changed regioselectivity & {$[18]$} \\
\hline \multirow[t]{3}{*}{ F87I } & Wild type & Geranyl acetone & More active; changed regioselectivity & {$[21]$} \\
\hline & A328I & $(+)$-Valencene & More active & {$[21]$} \\
\hline & A328V & Geranyl acetone, limonene & Less active & {$[21]$} \\
\hline F87S & Wild type & Lauric acid & Changed regioselectivity & [19] \\
\hline \multirow[t]{3}{*}{ F87Y } & Wild type & Lauric acid & Lower NADPH consumption; biphasic kinetics & [9] \\
\hline & Wild type & $N$-Palmitoyl glycine & Inactive; $100 \%$ uncoupled & {$[17]$} \\
\hline & Wild type & Arachidonic acid, eicopentenoic acid & Inactive; $100 \%$ uncoupled & [8] \\
\hline
\end{tabular}


Recently, several CYP102A1 mutants have been developed with the ability to metabolize drugs to human-relevant metabolites $[4,5]$. These mutants typically contain eight to ten mutations compared with wild-type CYP102A1, including mutations of Phe87. One versatile mutant developed in our laboratory is CYP102A1 M11, which has been constructed by a combination of site-directed mutagenesis, introducing R47L, F87V, and L188Q, and three subsequent rounds of random mutagenesis using four different alkoxyresorufins as substrates to screen for improved enzyme activity [5]. By the combination of eight mutations, when compared with wild-type CYP102A1, CYP102A1 M11 has acquired to ability to metabolize several drugs to high levels of human-relevant metabolites and reactive intermediates of drugs [22]. It would therefore be attractive to diversify this versatile enzyme to variants with novel regioselectivities. Because residue 87 plays a critical role in controlling substrate selectivity in wild-type CYP102A1 and mutants of CYP102A1 (Table 1), this residue was selected for mutagenesis in the present study. Recently, mutation F87A was shown to increase activity and enantioselectivity of buspirone metabolism when applied to CYP102A1 mutant 10-9A [16]. Other substitutions, however, were not evaluated. In this study, all 20 natural amino acids were evaluated at position 87 of CYP102A1 M11. Twelve of the possible amino acid substitutions have not been described previously in wild-type CYP102A1 or mutants of CYP102A1. The mutants were characterized using a homologous series of alkoxyresorufins and testosterone as substrates. Alkoxyresorufins are sensitive and useful probes to determine substrate selectivity of both bacterial and mammalian P450 isoforms by the continuous fluorimetric assay of resorufin formed by O-dealkylation [23-25]. Testosterone and other steroids have been shown to be hydroxylated by CYP102A1 mutants $[26,27]$. Testosterone is an excellent probe substrate to study the effect of position 87 on regioselectively because it can be hydroxylated at multiple positions dependent on the nature of P450 isoenzymes [28]. Furthermore, there is great interest in biocatalysts capable of stereoselectively and regioselectively hydroxylating steroids because steroid compounds rank among the most widely marketed products from the pharmaceutical industry [29]. We therefore studied whether regioselectivity of steroid hydroxylation by CYP102A1 can be manipulated by mutations at position 87 .

\section{Materials and methods}

Materials

All chemicals were of analytical grade and obtained from standard suppliers. Alkoxyresorufins (methoxyresorufin to $n$-octoxyresorufin) and benzyloxyresorufin were synthesized as described previously [24]. The pET28a+ vector containing wild-type CYP102A1 was kindly provided by V. Urlacher (Institut für Technische Biochemie, Universität Stuttgart, Germany).

\section{Library construction}

Site-directed mutants of CYP102A1 M11 at position 87 were constructed by mutagenic PCR using a Stratagene QuikChange XL site-directed mutagenesis kit (Stratagene, La Jolla, CA, USA) using 20 complementary pairs of mutagenesis primers. The mutagenic PCR was applied to a pBluescript vector (pBS p450 BM3 M11) containing the gene of the drug-metabolizing CYP102A1 M11, flanked by EcoRI and BamHI restriction sites. CYP102A1 M11 contains mutations R47L, E64G, F81I, F87V, E143G, L188Q, Y198C, E267V, H285Y, and G415S when compared with wild-type CYP102A1 [10]. The sequence of the forward primers was as follows: $5^{\prime}$-GCA GGA GAC GGG TTA XXX ACT AGT TGG ACG CAT- ${ }^{\prime}$. XXX represents the codon that was used to introduce the specific mutation at position 87 . The reverse primer for the mutagenic PCR was a 34-mer 5'-CAT GCG TCC AAC TAG TYY YTA ACC CGT CTC CTG C- $3^{\prime}$ in which

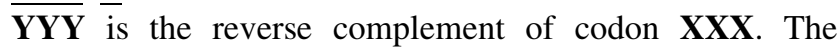
underlined bases indicate a new SpeI digestion site. The following codons (XXX) were used: Ala GCC, Arg CGG, Asn AAC, Asp GAC, Cys UGC, Gln CAG, Glu GAG, Gly GGG, His CAC, Ile AUC, Leu CUG, Lys AAG, Met AUG, Phe UUC, Pro CCC, Ser UCC, Thr ACC, Trp UGG, Tyr UAC, and Val GUG.

After mutagenic PCR, the plasmids were digested with EcoRI and BamHI restriction enzymes and the genes of mutated CYP102A1 M11 were cloned into a pET28a + vector, which encodes for an N-terminal Histag. The desired mutations in the P450 domain were confirmed by DNA sequencing (Baseclear, Leiden, The Netherlands).

Expression and purification of the mutants

Expression of the CYP102A1 mutants and wild-type CYP102A1 was performed by transforming competent Escherichia coli BL21 cells with the corresponding pET28+ vectors, as described previously [21]. Proteins were purified using nickel nitrilotriacetic acid agarose, after which $\mathrm{P} 450$ concentrations were determined according to the method of Omura and Sato [30]. The purity of the enzymes was checked by sodium dodecyl sulfate polyacrylamide gel electrophoresis on $12 \%$ gel and subsequent Coomassie staining. 
Metabolism of alkoxyresorufins by CYP102A1 mutants

The enzyme activities of the mutants and wild-type CYP102A1 toward a homologous series of alkoxyresorufins were measured according to the method of Burke et al. [23] with modifications.To determine O-dealkylation activities, fluorescence cuvettes (1.5-mL volume) were filled with $860 \mu \mathrm{L}$ of $100 \mathrm{mM}$ potassium phosphate buffer (pH 7.4), $20 \mu \mathrm{L}$ of $1 \mu \mathrm{M}$ CYP102A1 (20 nM final concentration), and $20 \mu \mathrm{L}$ of $1 \mathrm{mM}$ alkoxyresorufin in dimethyl sulfoxide (DMSO; final concentrations $20 \mu \mathrm{M}$ alkoxyresorufin, 2\% DMSO). After $30 \mathrm{~s}$ of preincubation, reactions were started by addition of $100 \mu \mathrm{L}$ of a mixture of $2 \mathrm{mM}$ NADPH, $3 \mathrm{mM}$ glucose 6-phosphate, and $0.4 \mathrm{U} / \mathrm{mL}$ glucose 6-phosphate dehydrogenase. The increase in fluorescence was monitored at an excitation wavelength of $532 \mathrm{~nm}$ and an emission wavelength of $586 \mathrm{~nm}$ for $2 \mathrm{~min}$ at $25^{\circ} \mathrm{C}$. Specific activities were determined in triplicate by measuring the initial slopes of resorufin formation. The Shimadzu RF-1501 spectrofluorometer used was calibrated by addition of $10 \mu \mathrm{L}$ of $1 \mu \mathrm{M}$ resorufin to the cuvette and by recording the increase in fluorescence [23]. The results are means of duplicate determinations, with duplicates typically differing by less than $5 \%$ from the mean.

To investigate involvement of hydroxylation of $n$-alkoxy substituents at other carbons, $10 \mu \mathrm{L}$ samples of incubations were analyzed by an Agilent 2000 ultraperformance liquid chromatography (UPLC) system using a Zorbax Eclipse XDB-C18 column $(1.8 \mu \mathrm{m}, 50 \mathrm{~mm} \times 4.6 \mathrm{~mm}$; Agilent, USA). Samples were eluted at a flow rate of $2 \mathrm{~mL} / \mathrm{min}$ using a gradient composed of solvent A $(99.8 \%$ water, $0.2 \%$ formic acid) and solvent B (99.8\% acetonitrile, $0.2 \%$ formic acid). The gradient was programmed as follows: from 0 to $1 \mathrm{~min}$ isocratic $40 \%$ solvent $\mathrm{B}$, from 1 to 8 min linear increase from 40 to $100 \%$ solvent $\mathrm{B}$, from 8 to $8.5 \mathrm{~min}$ isocratic $100 \%$ solvent $\mathrm{B}$, from 8.5 to 9 min linear decrease from 100 to $40 \%$ solvent $\mathrm{B}$, from 9 to $10 \mathrm{~min}$ isocratic $40 \%$ solvent B. Alkoxyresorufins were detected at $460 \mathrm{~nm}$. Under these conditions the following retention times were obtained: $2.84 \mathrm{~min}$ for methoxyresorufin, $3.57 \mathrm{~min}$ for ethoxyresorufin, $4.20 \mathrm{~min}$ for $n$-propoxyresorufin, $5.27 \mathrm{~min}$ for $n$-butoxyresorufin, $6.06 \mathrm{~min}$ for $n$-pentoxyresorufin, $6.82 \mathrm{~min}$ for $n$-hexoxyresorufin, $7.55 \mathrm{~min}$ for $n$-heptoxyresorufin, and $8.21 \mathrm{~min}$ for $n$-octoxyresorufin.

\section{Metabolism of testosterone by CYP102A1 mutants}

Incubations of CYP102A1 mutants $(200 \mathrm{nM})$ with testosterone $(0.5 \mathrm{mM})$ as the substrate were performed at $25{ }^{\circ} \mathrm{C}$ in a total volume of $250 \mu \mathrm{L}$ in $100 \mathrm{mM}$ potassium phosphate buffer ( $\mathrm{pH}$ 7.4). Reactions were started by adding $25 \mu \mathrm{L}$ of a mixture of $2 \mathrm{mM}$ NADPH, $3 \mathrm{mM}$ glucose 6-phosphate, and $4 \mathrm{U} / \mathrm{mL}$ glucose 6-phosphate dehydrogenase (final concentrations $0.2 \mathrm{mM}$ NADPH, $0.3 \mathrm{mM}$ glucose 6-phosphate, and $0.4 \mathrm{U} / \mathrm{mL}$ glucose 6-phosphate dehydrogenase), and were terminated after 60 min by addition of $250 \mu \mathrm{L}$ cold methanol. Samples were centrifuged for $15 \mathrm{~min}$ at $4,000 \mathrm{rpm}$, after which supernatants were transferred to high-performance liquid chromatography vials. Testosterone and metabolites were analyzed by high-resolution UPLC [31] using an Agilent 2000 system using a Zorbax Eclipse XDB-C18 column $(1.8 \mu \mathrm{m}, 50 \mathrm{~mm} \times 4.6 \mathrm{~mm}$; Agilent, USA). Metabolites and the substrate were eluted at a flow rate of $1.3 \mathrm{~mL} /$ min using a gradient composed of solvent A $(99.8 \%$ water, $0.2 \%$ formic acid) and solvent B (99.8\% methanol, $0.2 \%$ formic acid) The gradient was programmed as follows: from 0 to $2 \mathrm{~min}$ linear increase from 60 to $100 \%$ solvent $\mathrm{B}$, from 2 to $3 \mathrm{~min}$ isocratic $100 \%$ solvent $\mathrm{B}$, from 3 to 3.2 min linear decrease from 100 to $60 \%$ solvent $\mathrm{B}$, from 3.2 to $5 \mathrm{~min}$ isocratic $60 \%$ solvent B. Metabolites and the substrate were detected at $254 \mathrm{~nm}$.

\section{NADPH consumption}

NADPH consumption was quantified spectroscopically by monitoring the decrease in absorbance at $340 \mathrm{~nm}$ using an extinction coefficient of $6,210 \mathrm{M}^{-1} \mathrm{~cm}^{-1}$. Cuvettes (1.5$\mathrm{mL}$ volume; $1 \mathrm{~cm}$ path length) were filled with $880 \mu \mathrm{L}$ of $100 \mathrm{mM}$ potassium phosphate buffer ( $\mathrm{pH} 7.4)$ and $20 \mu \mathrm{L}$ of $1 \mu \mathrm{M}$ CYP102A1 mutant (final concentration $20 \mathrm{nM}$ ). Reactions were performed at $25{ }^{\circ} \mathrm{C}$ and started by addition of $100 \mu \mathrm{L}$ of $2 \mathrm{mM}$ NADPH (final concentration $200 \mu \mathrm{M}$ ), after which the decrease of NADPH was monitored for 2 min. To determine substrate-induced NADPH consumption, cuvettes were filled with $860 \mu \mathrm{L}$ of $100 \mathrm{mM}$ potassium phosphate buffer ( $\mathrm{pH} 7.4), 20 \mu \mathrm{L}$ of $1 \mathrm{mM}$ alkoxyresorufin (dissolved in DMSO), and $20 \mu \mathrm{L}$ of $1 \mu \mathrm{M}$ CYP102A1 mutant. Reactions were started by addition of $100 \mu \mathrm{L}$ of $2 \mathrm{mM}$ NADPH, after which the decrease of NADPH was monitored for $2 \mathrm{~min}$. To correct for the solvent DMSO, incubations were also performed by adding $20 \mu \mathrm{L}$ DMSO.

The coupling efficiencies of the CYP102A1 mutants which were able to metabolize alkoxyresorufins were calculated from the ratio of the initial rate of product formation and the initial rate of NADPH consumption.

To investigate whether NADPH consumption is induced by binding to the substrate binding site, incubations were also performed in the presence of $1 \mu \mathrm{M}$ ketoconazole, which was shown to be a very potent inhibitor of CYP102A1 mutants, including CYP102A1 M11 [13, 32]. To test whether wild-type CYP102A1 can also be inhibited by ketoconazole, inhibition of NADPH consumption induced by $100 \mu \mathrm{M}$ lauric acid was studied. 
UV-vis spectroscopy

For a selection of the CYP102A1 mutants, the type of substrate binding and the spectral dissociation constants $\left(K_{\mathrm{D}}\right)$ were determined for four substituted resorufins (methoxyresorufin, $n$-butoxyresorufin, $n$-heptoxyresorufin, and benzyloxyresorufin) using UV-vis difference spectroscopy. UV-vis spectra were recorded at room temperature using a Shimadzu UV-2501PC spectrophotometer (Shimadzu Duisburg, Germany). All substrate-induced binding spectra were recorded using tandem cuvettes (10-mm path length) to eliminate absorbance by alkoxyresorufins. Briefly, $1 \mathrm{~mL}$ of $2 \mu \mathrm{M}$ enzyme in $100 \mathrm{mM}$ potassium phosphate buffer ( $\mathrm{pH}$ 7.4) was added to one of the chambers of the sample and reference tandem cuvette. The other chambers were filled with an equal volume of $100 \mathrm{mM}$ potassium phosphate buffer. The enzyme-containing chamber of the sample cuvette was titrated with microliter volumes of ethanol solutions of alkoxyresorufins, resulting in final concentrations ranging from 1 to $30 \mu \mathrm{M}$. In the reference cuvette, the same volume of alkoxyresorufin solution was added to the chamber containing buffer only. To correct for effects of ethanol, equal volumes of ethanol were added to the chambers without alkoxyresorufin. At each concentration of substrate, a UV-vis difference spectrum was recorded from 500 to $350 \mathrm{~nm}$. The observed differences in absorption between $390 \mathrm{~nm}$ (peak) and $419 \mathrm{~nm}$ (trough), $\Delta A_{390-419}$, were plotted versus alkoxyresorufin concentration after correction for dilution and were analyzed by nonlinear regression using GraphPad Prism 4 (GraphPad Sotware, San Diego, CA, USA). The spectral dissociation constants $\left(K_{\mathrm{D}}\right)$ were determined by fitting the titration binding curves using to the following equation:

$\Delta A_{390-419}=\frac{\Delta A_{\infty} \times[S]}{K_{\mathrm{D}}+[S]}$

where $\Delta A_{\infty}$ represents the maximal difference at saturating alkoxyresorufin concentration and $K_{\mathrm{D}}$ is the dissociation constant of the enzyme-substrate complex.

\section{Results}

Expression and characterization of the CYP102A1 M11 mutants

Transformation of $E$. coli BL21 with the pET28+ vectors encoding the different CYP102A1 M11 mutants and subsequent purification resulted in significantly different yields of CYP102A1 mutants, ranging from 27 to 666 nmol P450 per liter original growth medium (Table 2). After purification by nickel nitrilotriacetic acid agarose, protein purity was always higher than $98 \%$ according to sodium dodecyl sulfate polyacrylamide gel electrophoresis. For four of the purified mutants containing Pro87, Asp87, Glu87, and Ser87, the reduced CO difference spectra only showed a peak at $420 \mathrm{~nm}$. Formation of P420 is considered to result from coordination of a neutral thiol (in the case of CYP102A1 Cys400) to the heme iron, instead of a thiolate, which is required to produce the active P450 [33]. Mutation F87S, when applied to wild-type CYP102A1, was previously shown to be an active enzyme with changed regioselectivity in lauric acid hydroxylation [19]. However, CO difference spectroscopy only showed P420, suggesting that Ser87 is denaturing owing to sodium dithionite treatment (V. Urlacher, personal communication). Because the concentration of these mutants could not be quantified, they were not further evaluated in our metabolism experiments. The mutant containing Asn87 showed a significant peak at $420 \mathrm{~nm}$ with intensity almost equal to that at $450 \mathrm{~nm}$. Mutants containing Met87, His87, and Gly87 showed a small shoulder at $420 \mathrm{~nm}$ next to the peak at $450 \mathrm{~nm}$. All other mutants only produced peaks with maxima ranging from 448 and $450 \mathrm{~nm}$.

\section{Alkoxyresorufin metabolism by the CYP102A1 M11 mutants}

\section{O-dealkylation activities}

Table 3 shows that the specific activities of O-dealkylation of nine different alkoxyresorufins measured in incubations with 16 variants of CYP102A1 M11 were very strongly affected by the nature of the amino acid at position 87 . On average, the highest $\mathrm{O}$-dealkylation activities were observed with mutants containing nonpolar side chains Ala87, Gly87, and Val87. Of the polar residues, Tyr87 was most active, showing significant activity with all alkoxyresorufins, except with methoxyresorufin as the substrate. The mutants containing the charged residues only showed low activities toward all alkoxyresorufins. Under the present conditions, Lys87, Met87, and Trp87 did not show significant O-dealkylation activity with any alkoxyresorufin.

When comparing O-dealkylation activity between the different $n$-alkoxy-substituted substrates (methoxyresorufin to $n$-octoxyresorufin), we found that the compounds with the shortest $n$-alkoxy substituent were poorly metabolized. Methoxyresorufin was not O-demethylated by any of the mutants, whereas for ethoxyresorufin and $n$-propoxyresorufin only two and three mutants, respectively, showed activity. The longer the $n$-alkoxy group, the more enzymes showed activity, although to very different extents. The three most active mutants, Gly87, Ala87, and Val87, and mutant Tyr87 all showed the highest activity with $n$-pentoxyresorufin as the substrate; both increasing and 
Table 2 Spectroscopic properties and yields of the CYP102A1 M11 mutants
$N D$ no detectable peak at $450 \mathrm{~nm}, N Q$ not quantifiable owing to the absence of a peak at $450 \mathrm{~nm}$

${ }^{a}$ CYP102A1 M11 containing R47L, E64G, F81I, F87V, E143G, L188Q, E267V, and G415S [9]

\begin{tabular}{|c|c|c|c|c|}
\hline \multirow[t]{2}{*}{ No. } & \multirow[t]{2}{*}{ Residue } & \multicolumn{2}{|c|}{ Reduced-CO difference spectra } & \multirow{2}{*}{$\begin{array}{l}\mathrm{P} 450 \text { yield (nmol/L } \\
\text { growth medium) }\end{array}$} \\
\hline & & Maximum (nm) & $A_{450} / A_{420}$ ratio & \\
\hline \multicolumn{5}{|c|}{ Nonpolar side chain } \\
\hline 1 & Phe87 & 450 & $>100$ & 165 \\
\hline 2 & Gly87 & 423,449 & 78 & 148 \\
\hline 3 & Ala87 & 449 & $>100$ & 51 \\
\hline 4 & Leu87 & 449 & $>100$ & 237 \\
\hline 5 & Ile87 & 449 & $>100$ & 581 \\
\hline 6 & Val87 ${ }^{\mathrm{a}}$ & 449 & $>100$ & 666 \\
\hline 7 & Met87 & 423,448 & 12.1 & 344 \\
\hline 8 & Pro87 & 420 & ND & NQ \\
\hline 9 & $\operatorname{Trp} 87$ & 450 & $>100$ & 27 \\
\hline \multicolumn{5}{|c|}{ Uncharged polar side chain } \\
\hline 10 & Ser87 & 422 & ND & NQ \\
\hline 11 & Thr87 & 449 & $>100$ & 203 \\
\hline 12 & Asn87 & 421,450 & 1.2 & 132 \\
\hline 13 & Gln87 & 448 & $>100$ & 49 \\
\hline 14 & Tyr87 & 448 & $>100$ & 585 \\
\hline 15 & Cys87 & 450 & $>100$ & 41 \\
\hline \multicolumn{5}{|c|}{ Charged polar side chain } \\
\hline 16 & Lys87 & 448 & $>100$ & 91 \\
\hline 17 & $\operatorname{Arg} 87$ & 449 & $>100$ & 173 \\
\hline 18 & His87 & 423,450 & 5.8 & 80 \\
\hline 19 & Asp87 & 420 & ND & NQ \\
\hline 20 & Glu87 & 420 & ND & NQ \\
\hline
\end{tabular}

which would not result in O-dealkylation, incubations were analyzed by UPLC with detection at $460 \mathrm{~nm}$, which is the absorption maximum of all alkoxyresorufins, independent of the nature of the $n$-alkoxy substituent. Chromatograms of these incubations measured at $460 \mathrm{~nm}$ showed only strong peaks of the unchanged alkoxyresorufin substrates. Only extremely small peaks (less than $3 \%$ of parent compound) were found (data not shown), indicating that sidechain hydroxylations did not occur to a significant extent.

\section{NADPH consumption and coupling efficiency}

Table 4 shows the specific activities of the alkoxyresorufindependent NADPH consumption in incubations with CYP102A1 M11 mutants and wild-type CYP102A1. The incubation conditions were similar to those for the fluorimetric O-dealkylation assays, except that the NADPHregenerating system was excluded to enable NADPH consumption to be measured. Surprisingly, all of the mutants tested showed a very high specific activity in NADPH consumption. The highest activities were found in incubations with the mutant containing residue His87. This mutant showed specific activities higher than $6,000 \mathrm{nmol}$ $\mathrm{NADPH} / \mathrm{min} / \mathrm{nmol} \mathrm{P} 450$, leading to complete consumption of NADPH within 4 min. The lowest activities were found 
Table 3 Specific activities (nmol resorufin/min/nmol P450) of alkoxyresorufin O-dealkylation by CYP102A1 M11 mutants and wild-type CYP102A1

\begin{tabular}{|c|c|c|c|c|c|c|c|c|c|c|}
\hline \multirow[t]{2}{*}{ No. } & \multirow[t]{2}{*}{ Residue } & \multicolumn{9}{|c|}{ Side chain } \\
\hline & & Methyl & Ethyl & $n$-Propyl & n-Butyl & $n$-Pentyl & $n$-Hexyl & $n$-Heptyl & $n$-Octyl & Benzyl \\
\hline \multicolumn{11}{|c|}{ Nonpolar side chain } \\
\hline 1 & Phe87 & ND & ND & ND & ND & ND & 0.11 & 0.16 & 0.060 & 0.29 \\
\hline 2 & Gly87 & ND & ND & ND & 1.01 & 3.80 & 2.59 & 0.74 & 0.14 & 4.02 \\
\hline 3 & Ala87 & ND & 0.16 & 1.53 & 4.37 & 11.05 & 1.83 & 0.34 & 0.10 & 3.79 \\
\hline 4 & Leu87 & ND & ND & ND & ND & 0.042 & 0.024 & 0.051 & 0.024 & 0.23 \\
\hline 5 & Ile87 & ND & ND & ND & ND & 0.35 & 0.010 & 0.062 & ND & 0.031 \\
\hline 6 & Val $87^{\mathrm{a}}$ & ND & ND & 0.75 & 1.08 & 1.64 & 0.42 & 0.11 & 0.068 & 5.43 \\
\hline 7 & Met87 & ND & ND & ND & ND & ND & ND & ND & ND & ND \\
\hline 8 & Pro87 & - & - & - & - & - & - & - & - & - \\
\hline 9 & Trp87 & ND & ND & ND & ND & ND & ND & ND & ND & ND \\
\hline \multicolumn{11}{|c|}{ Uncharged polar side chain } \\
\hline 10 & Ser87 & - & - & - & - & - & - & - & - & - \\
\hline 11 & Thr87 & ND & ND & ND & 0.12 & ND & 0.10 & 0.055 & 0.060 & 0.12 \\
\hline 12 & Asn87 & ND & ND & ND & ND & ND & 0.021 & 0.053 & 0.057 & 0.14 \\
\hline 13 & Gln87 & ND & ND & ND & ND & ND & 0.077 & 0.097 & 0.064 & 0.51 \\
\hline 14 & Tyr87 & ND & 0.024 & 0.13 & 0.14 & 0.55 & 0.076 & 0.017 & 0.031 & 0.92 \\
\hline 15 & Cys87 & ND & ND & ND & ND & ND & 0.026 & ND & ND & ND \\
\hline \multicolumn{11}{|c|}{ Charged polar side chain } \\
\hline 16 & Lys87 & ND & ND & ND & ND & ND & ND & ND & ND & ND \\
\hline 17 & Arg87 & ND & ND & ND & ND & ND & 0.013 & 0.010 & 0.028 & 0.038 \\
\hline 18 & His87 & ND & ND & ND & ND & ND & 0.046 & 0.022 & 0.046 & ND \\
\hline 19 & Asp87 & - & - & - & - & - & - & - & - & - \\
\hline 20 & Glu87 & - & - & - & - & - & - & - & - & - \\
\hline 21 & Wild type (Phe87) & ND & ND & ND & ND & ND & ND & 0.17 & 0.18 & ND \\
\hline
\end{tabular}

Specific activities observed with $20 \mu \mathrm{M}$ alkoxyresorufin and $20 \mathrm{nM}$ P450 BM3. THe values represent averages of three measurements, standard deviations were less than $10 \%$

$N D$ not detectable (less than $0.01 \mathrm{nmol} / \mathrm{min} / \mathrm{nmol} \mathrm{P} 450$ )

${ }^{a}$ CYP102A1 M11 containing R47L, E64G, F81I, F87V, E143G, L188Q, E267V, and G415S [22]

in mutants containing residues Tyr87, Ile87, Leu87, and Met87. Interestingly, for each mutant NADPH consumption was more or less similar for the substrates with the shorter $n$-alkoxy substituents, methoxyresorufin to $n$-pentoxyresorufin and allyloxyresorufin. For each mutant, the activities with these substrates varied by only $10-15 \%$, which is close to the analytical error. These results suggest that for these alkoxyresorufins, NADPH oxidation is not influenced by the length of the $n$-alkoxy group. For substrates with longer $n$-alkoxy substituents, $n$-hexoxyresorufin to $n$-octoxyresorufin, NADPH oxidation gradually decreased with increasing $n$-alkoxy chain length. Also, in the case of benzyloxyresorufin, having a bulky O-substituent, significantly lower NADPH consumption was observed than for the other substrates.

Because no significant other metabolic pathways (sidechain hydroxylation) were found, the coupling efficiencies of the mutants were calculated from the ratio of the specific activities of resorufin production and NADPH consumption (Table 5). Because of the very high rates of NADPH consumption for all combinations of substrates and enzymes, extremely low coupling efficiencies were found. The highest coupling efficiencies were found with mutants containing Ala87 and Val87, with the highest coupling efficiencies of $0.68 \%$ (n-pentyl) and $0.75 \%$ (benzyl), respectively. For most reactions, the coupling efficiencies were too low to quantify because O-dealkylation activities were below the limit of detection.

To test whether NADPH consumption induced by alkoxyresorufin is the result of binding to the substrate binding site, we investigated whether $1 \mu \mathrm{M}$ ketoconazole was able to block NADPH consumption in incubations of wild-type CYP102A1 and mutant Val87 (M11). To test whether this concentration of ketoconazole was able to inhibit CYP102A1, we first investigated whether it was able to block NADPH consumption induced by $0.1 \mathrm{mM}$ lauric 
Table 4 Specific activities (nmol NADPH/min/nmol P450) of alkoxyresorufin-induced NADPH consumption by CYP102A1 M11 mutants and wild-type CYP102A1

\begin{tabular}{|c|c|c|c|c|c|c|c|c|c|c|c|}
\hline \multirow[t]{2}{*}{ No. } & \multirow[t]{2}{*}{ Residue } & \multicolumn{9}{|c|}{ Side chain } & \multirow[t]{2}{*}{ DMSO } \\
\hline & & Methyl & Ethyl & $n$-Propyl & n-Butyl & $n$-Pentyl & $n$-Hexyl & $n$-Heptyl & n-Octyl & Benzyl & \\
\hline \multicolumn{12}{|c|}{ Nonpolar side chain } \\
\hline 1 & Phe87 & 4,100 & 4,590 & 3,640 & 4,520 & 4,290 & 3,120 & 1,150 & 370 & 2,170 & $<10$ \\
\hline 2 & Gly87 & 4,380 & 3,910 & 3,950 & 4,440 & 4,170 & 2,200 & 960 & 300 & 2,360 & 105 \\
\hline 3 & Ala87 & 1,860 & 1,800 & 1,510 & 1,910 & 1,620 & 550 & 300 & 130 & 950 & 90 \\
\hline 4 & Leu87 & 1,180 & 1,120 & 960 & 1,110 & 540 & 260 & 270 & 190 & 190 & 95 \\
\hline 5 & Ile87 & 820 & 930 & 770 & 730 & 360 & 180 & 100 & 110 & 200 & 85 \\
\hline 6 & Val $87^{\mathrm{a}}$ & 2,930 & 2,660 & 2,590 & 3,180 & 2,100 & 900 & 290 & 310 & 720 & 190 \\
\hline 7 & Met87 & 1,030 & 760 & 660 & 920 & 880 & 140 & 110 & 75 & 400 & 25 \\
\hline 8 & Pro87 & - & - & - & - & - & - & - & - & - & - \\
\hline 9 & Trp87 & 2,090 & 1,790 & 1,450 & 1,880 & 1,980 & 870 & 320 & 130 & 1,450 & 45 \\
\hline \multicolumn{12}{|c|}{ Uncharged polar side chain } \\
\hline 10 & Ser87 & - & - & - & - & - & - & - & - & - & - \\
\hline 11 & Thr87 & 1,910 & 1,570 & 1,530 & 1,900 & 1,890 & 800 & 470 & 260 & 480 & $<10$ \\
\hline 12 & Asn87 & 3,260 & 2,950 & 2,450 & 2,920 & 2,970 & 1,530 & 730 & 250 & 2,260 & $<10$ \\
\hline 13 & Gln87 & 1,860 & 1,740 & 1,510 & 1,770 & 1,920 & 700 & 420 & 200 & 1,130 & 40 \\
\hline 14 & Tyr87 & 700 & 680 & 620 & 710 & 690 & 400 & 130 & 87 & 370 & $<10$ \\
\hline 15 & Cys87 & 3,570 & 3,490 & 3,030 & 3,430 & 3,470 & 1,590 & 560 & 150 & 2,370 & 35 \\
\hline \multicolumn{12}{|c|}{ Charged polar side chain } \\
\hline 16 & Lys87 & 3,570 & 3,400 & 3,080 & 4,100 & 3,780 & 1,580 & 600 & 210 & 2,220 & $<10$ \\
\hline 17 & Arg87 & 3,740 & 3,780 & 2,950 & 3,400 & 2,970 & 840 & 240 & 97 & 1,330 & 25 \\
\hline 18 & His87 & 6,110 & 6,080 & 5,650 & 5,600 & 5,600 & 2,240 & 1,650 & 890 & 5,100 & $<10$ \\
\hline 19 & Asp87 & - & - & - & - & - & - & - & - & - & - \\
\hline 20 & Glu87 & - & - & - & - & - & - & - & - & - & - \\
\hline 21 & Wild type (Phe87) & 4,650 & 3,970 & 3,290 & 4,220 & 4,020 & 2,260 & 1,030 & 730 & 4,110 & 45 \\
\hline
\end{tabular}

The values represent averages of three measurements; standard deviations were less than $10 \%$

DMSO dimethyl sulfoxide

${ }^{a}$ CYP102A1 M11 containing R47L, E64G, F81I, F87V, E143G, L188Q, E267V, and G415S [22]

acid. With both wild-type CYP102A1 and mutant Val87, lauric acid strongly stimulated NADPH consumption. Addition of $1 \mu \mathrm{M}$ ketoconazole completely blocked lauric acid induced NADPH consumption of both enzymes. When wild-type CYP102A1 and mutant Val87 (M11) were tested with benzyloxyresorufin as the substrate, ketoconazole was also able to almost completely block substrateinduced NADPH consumption as well as the O-dealkylation reaction (data not shown).

\section{Binding spectra}

Titration of alkoxyresorufins to solutions of CYP102A1 and the two selected CYP102A1 M11 mutants in all cases resulted in typical type I difference spectra with a peak at $390 \mathrm{~nm}$ and a trough at $419 \mathrm{~nm}$ (data not shown), indicative of the conversion of the heme iron from low spin to high spin. Table 6 shows the dissociation constants $\left(K_{\mathrm{D}}\right)$ obtained by nonlinear fitting of the $\Delta A_{390-419}$ versus substrate concentration curves, after correction for dilution. Surprisingly, methoxyresorufin, which is not O-demethylated by any of the mutants, binds to the selected mutants with relatively high affinity with binding constants ranging from 2.4 to $8 \mu \mathrm{M}$ (Table 6). Because enzyme activity measurements were carried out with $20 \mu \mathrm{M}$ substrate, it can be concluded that the lack of O-dealkylation is most likely due to nonproductive binding rather than lack of affinity for the enzyme. Wild-type CYP102A1, which only showed very low O-dealkylation activity toward $n$-heptoxyresorufin, showed higher affinity for the other alkoxyresorufins which are not O-dealkylated. CYP102A1 M11 mutants containing Ala87 and Val87, which generally showed relatively high O-dealkylation activity, showed slightly higher affinity for the alkoxyresorufins than wildtype CYP102A1. The only substrate showing significantly lower affinity for wild-type CYP102A1 when compared with the CYP102A1 mutants was $n$-heptoxyresorufin (Fig. 1). 
Table 5 Coupling efficiency (\%) of alkoxyresorufin O-dealkylation by CYP102A1 M11 mutants and wild-type CYP102A1

\begin{tabular}{|c|c|c|c|c|c|c|c|c|c|c|}
\hline \multirow[t]{2}{*}{ No. } & \multirow[t]{2}{*}{ Residue } & \multicolumn{9}{|c|}{ Side chain } \\
\hline & & Methyl & Ethyl & $n$-Propyl & n-Butyl & $n$-Pentyl & $n$-Hexyl & $n$-Heptyl & $n$-Octyl & Benzyl \\
\hline \multicolumn{11}{|c|}{ Nonpolar side chain } \\
\hline 1 & Phe87 & ND & ND & ND & ND & ND & 0.004 & 0.014 & 0.016 & 0.013 \\
\hline 2 & Gly87 & ND & ND & ND & 0.023 & 0.091 & 0.118 & 0.077 & 0.047 & 0.170 \\
\hline 3 & Ala87 & ND & ND & 0.101 & 0.229 & 0.682 & 0.333 & 0.113 & 0.077 & 0.399 \\
\hline 4 & Leu87 & ND & ND & ND & ND & 0.008 & 0.009 & 0.019 & 0.013 & 0.121 \\
\hline 5 & Ile87 & ND & ND & ND & ND & 0.097 & 0.006 & 0.062 & ND & 0.016 \\
\hline 6 & $\mathrm{Val} 87^{\mathrm{a}}$ & ND & ND & 0.029 & 0.034 & 0.078 & 0.047 & 0.038 & 0.022 & 0.754 \\
\hline 7 & Met87 & ND & ND & ND & ND & ND & ND & ND & ND & ND \\
\hline 8 & Pro87 & - & - & - & - & - & - & - & - & - \\
\hline 9 & $\operatorname{Trp} 87$ & ND & ND & ND & ND & ND & ND & ND & ND & ND \\
\hline \multicolumn{11}{|c|}{ Uncharged polar side chain } \\
\hline 10 & Ser87 & - & - & - & - & - & - & - & - & - \\
\hline 11 & Thr87 & ND & ND & ND & 0.006 & ND & 0.013 & 0.012 & 0.023 & 0.025 \\
\hline 12 & Asn87 & ND & ND & ND & ND & ND & 0.001 & 0.007 & 0.023 & 0.006 \\
\hline 13 & Gln87 & ND & ND & ND & ND & ND & 0.011 & 0.023 & 0.032 & 0.045 \\
\hline 14 & Tyr87 & ND & 0.004 & 0.021 & 0.020 & 0.080 & 0.019 & 0.013 & 0.036 & 0.249 \\
\hline 15 & Cys87 & ND & ND & ND & ND & ND & 0.002 & ND & ND & ND \\
\hline \multicolumn{11}{|c|}{ Charged polar side chain } \\
\hline 16 & Lys87 & ND & ND & ND & ND & ND & ND & ND & ND & ND \\
\hline 17 & $\operatorname{Arg} 87$ & ND & ND & ND & ND & ND & 0.002 & 0.042 & 0.029 & 0.003 \\
\hline 18 & His87 & ND & ND & ND & ND & $\mathrm{ND}$ & 0.002 & 0.001 & 0.005 & ND \\
\hline 19 & Asp87 & - & - & - & - & - & - & - & - & - \\
\hline 20 & Glu87 & - & - & - & - & - & - & - & - & - \\
\hline 21 & Wild type (Phe87) & ND & ND & ND & ND & ND & ND & 0.016 & 0.025 & ND \\
\hline
\end{tabular}

Coupling efficiencies were calculated by the following formula: specific activity of resorufin production (Table 3)/specific activity of NADPH consumption (Table 4$) \times 100 \%$

$N D$ not detectable $(<0.001 \%)$

${ }^{a}$ P450 BM3 M11 containing R47L, E64G, F81I, F87V, E143G, L188Q, E267V, and G415S [22]

Table 6 Alkoxyresorufin binding by wild-type CYP102A1 and CYP102A1 M11 mutants

\begin{tabular}{|c|c|c|c|c|}
\hline \multirow[t]{2}{*}{ Substrate } & \multicolumn{4}{|l|}{$K_{\mathrm{D}}(\mu \mathrm{M})^{\mathrm{a}}$} \\
\hline & Methoxyresorufin & $n$-Butoxyresorufin & $n$-Heptoxyresorufin & Benzyloxyresorufin \\
\hline CYP102A1 (wild type) & $8.4 \pm 1.4$ & $1.6 \pm 0.2$ & $22 \pm 6.4$ & $2.7 \pm 0.4$ \\
\hline CYP102A1 M11 Ala87 & $4.0 \pm 0.5$ & $1.1 \pm 0.1$ & $4.9 \pm 0.4$ & $1.4 \pm 0.3$ \\
\hline CYP102A2 M11 Val87 & $2.4 \pm 0.2$ & $0.8 \pm 0.1$ & $1.4 \pm 0.2$ & $1.8 \pm 0.3$ \\
\hline
\end{tabular}

${ }^{a}$ Dissociation constants were determined by difference spectroscopy using $2 \mu \mathrm{M}$ enzyme in $100 \mathrm{mM}$ potassium phosphate buffer, pH 7.4, titrated with a solution of substrate. All substrates produced a type I binding spectrum with a peak at $390 \mathrm{~nm}$ and trough at $419 \mathrm{~nm}$. The data for the absorbance at $419 \mathrm{~nm}$ minus the absorbance at 390 were corrected for dilution and fitted to an equation for a bimolecular association reaction to obtain the dissociation constant

Testosterone hydroxylation by the CYP102A1 M11 mutants

Analysis of incubations of the CYP102A1 mutants with testosterone by UPLC showed three major metabolites were produced that were eluted at $0.93,1.48$, and $1.69 \mathrm{~min}$.
These metabolites corresponded to the three hydroxytestosterone metabolites previously observed with triplemutant CYP102A1 R47L/F87V/L188Q [26]. Figure 2 shows the chromatograms obtained after incubations of testosterone with mutants containing residues Tyr87, Ala87, Phe87, and Ile87, since they are representative of 
Fig. 1 Structures and reactions of substrates used to characterize the CYP102A1 mutants. a Alkoxyresorufin O-dealkylation:

$\mathrm{R}$ is:

$\mathrm{H}$ (methoxyresorufin),

$\mathrm{CH}_{3}$ (ethoxyresorufin),

$\mathrm{C}_{2} \mathrm{H}_{5}$ (n-propoxyresorufin),

$\mathrm{C}_{3} \mathrm{H}_{7}$ (n-butoxyresorufin),

$\mathrm{C}_{4} \mathrm{H}_{9}$ (n-pentoxyresorufin),

$\mathrm{C}_{5} \mathrm{H}_{11}$ (n-hexoxyresorufin),

$\mathrm{C}_{6} \mathrm{H}_{13}$ (n-heptoxyresorufin),

$\mathrm{C}_{7} \mathrm{H}_{15}$ (n-octoxyresorufin),

$\mathrm{C}_{6} \mathrm{H}_{5}$ (benzyloxyresorufin).

b Testosterone hydroxylation:

arrows indicate identified

positions of hydroxylation

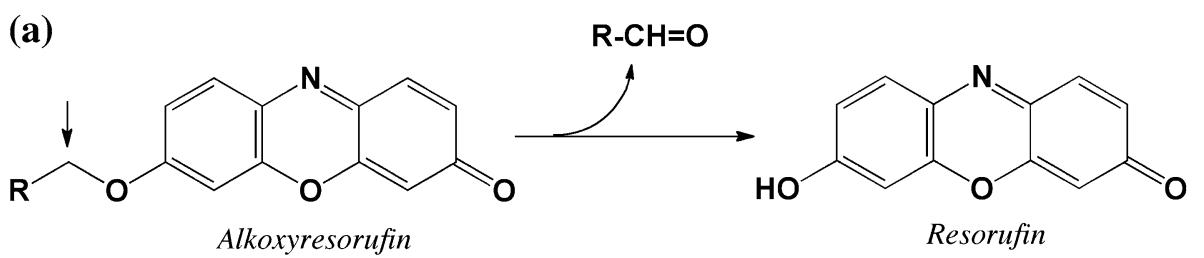

(b)

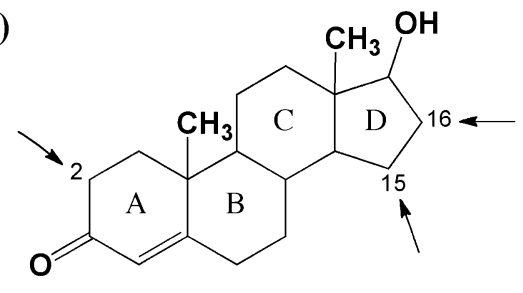

Testosterone

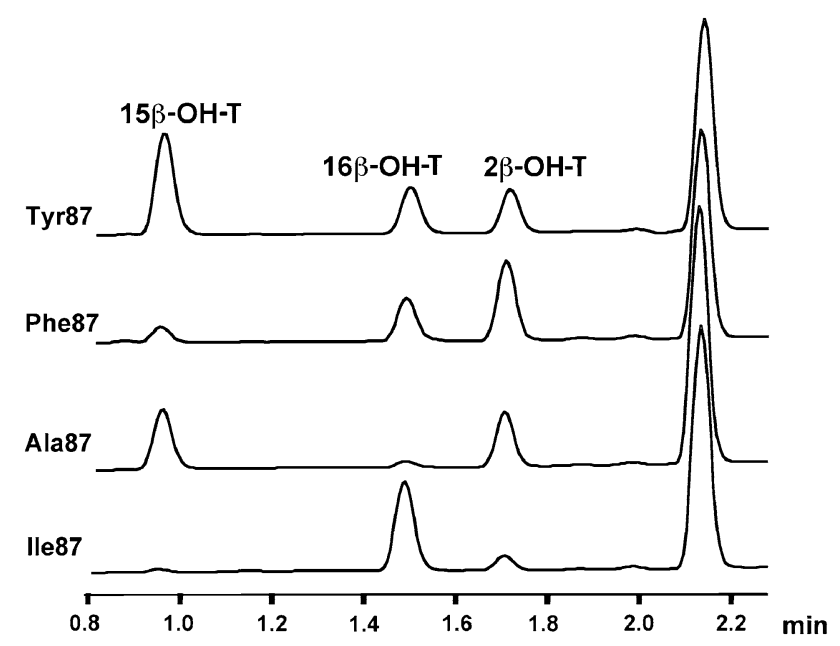

Fig. 2 Ultraperformance liquid chromatography chromatograms obtained after incubations of testosterone $(0.5 \mathrm{mM})$ with a selection of CYP102A1 mutants $(200 \mathrm{nM})$, representing the diversity in regioselectivity. $\quad 15 \beta-O H-T \quad 15 \beta$-hydroxytestosterone, $16 \beta-O H-T$ $16 \beta$-hydroxytestosterone, $2 \beta-O H-T 2 \beta$-hydroxytestosterone

the diversity in the metabolic profiles obtained. The metabolite eluted at 1.48 min was previously identified as $16 \beta$-hydroxytestosterone (16 $\beta$-OH-T) [26]. For structure elucidation of the other metabolites, large-scale $(50-\mathrm{mL})$ incubations were performed for $3 \mathrm{~h}$ containing $250 \mathrm{nM}$ mutant Val87 (P450 M11), $500 \mu \mathrm{M}$ testosterone, $0.2 \mathrm{mM}$ $\mathrm{NADPH}$, and a regenerating system $(0.3 \mathrm{mM}$ glucose 6-phosphate and $0.4 \mathrm{U} / \mathrm{mL}$ glucose 6-phosphate dehydrogenase). Metabolites were extracted by dichloromethane and isolated by preparative high-performance liquid chromatography. Structure identification was performed by a combination of ${ }^{1} \mathrm{D}-{ }^{1} \mathrm{H},{ }^{1} \mathrm{H}-{ }^{1} \mathrm{H}$ double-quantum-filtered correlation spectroscopy, ${ }^{1} \mathrm{H}_{-}{ }^{13} \mathrm{C}$ heteronuclear single quantum coherence, ${ }^{1} \mathrm{H}_{-}{ }^{13} \mathrm{C}$ heteronuclear multiple quantum correlation, ${ }^{1} \mathrm{H}_{-}{ }^{13} \mathrm{C}$ heteronuclear multiple bond correlation, and ${ }^{1} \mathrm{H}-{ }^{1} \mathrm{H}$ nuclear Overhauser effect spectroscopy NMR experiments [34]. The metabolite eluted at $0.93 \mathrm{~min}$ was identified as $15 \beta$-hydroxytestosterone $(15 \beta-\mathrm{OH}-\mathrm{T})$, whereas the metabolite eluted at $1.69 \mathrm{~min}$ was identified as $2 \beta$-hydroxytestosterone ( $2 \beta$-OH-T). These two metabolites were previously also identified by similar NMR experiments as products formed in incubations of testosterone with housefly cytochrome P450 (CYP6A1) [35]. Very minor metabolites were eluted at 1.85 and $1.95 \mathrm{~min}$; however, the concentrations of these metabolites were too low to allow structural assignment.

As shown in Table 7, all mutants were able to hydroxylate testosterone with widely different activities and with significant differences in metabolic profiles. The most active mutants were Tyr87, Val87, Thr87, Phe87, Ile87, and Ala87 (in decreasing order); the other mutants showed activities less than $10 \%$ of that of Tyr87. In general, mutants having a very low activity with alkoxyresorufins as substrates also showed a low activity with testosterone as the substrate, except for the mutants containing Phe87 and Thr87, which showed relatively high activity of testosterone hydroxylation. Incubation of wild-type CYP102A1 did not show formation of any metabolites.

Figure 3 shows the metabolic profiles of the mutants ordered according to similarities in the metabolic profiles, and by preference for hydroxylation of the D-ring (e.g., $15 \beta$-hydroxylation and $16 \beta$-hydroxylation) versus the A-ring ( $2 \beta$-hydroxylation). Numbers below the bars represent the ratio of D-ring to A-ring hydroxylation as calculated from the sum of peak areas of $15 \beta-\mathrm{OH}-\mathrm{T}$ and $16 \beta$-OH-T, divided by the peak area of $2 \beta$-OH-T.

Mutants containing residues Ile87, Val87, Gly87, Tyr87, Trp87, and Ala87 all showed a preference for hydroxylation of the D-ring of testosterone. For mutants containing Val87, Gly87, Tyr87, and Trp87 very similar profiles were 
Table 7 Total activity and unit of activity (nmol hydroxytestosterone/nmol P450/h) of testosterone hydroxylation by CYP102A1 M11 mutants and wild-type CYP102A1

\begin{tabular}{|c|c|c|c|c|c|}
\hline \multirow[t]{2}{*}{ No. } & \multirow[t]{2}{*}{ Residue } & \multicolumn{4}{|c|}{ Metabolite formation ${ }^{a}$} \\
\hline & & $15 \beta-\mathrm{OH}-\mathrm{T}$ & $16 \beta-\mathrm{OH}-\mathrm{T}$ & $2 \beta-\mathrm{OH}-\mathrm{T}$ & $\begin{array}{l}\text { Total } \\
\text { activity }\end{array}$ \\
\hline \multicolumn{6}{|c|}{ Nonpolar side chain } \\
\hline 1 & Phe87 & 86 & 275 & 499 & 860 \\
\hline 2 & Gly87 & 31 & 13 & 12 & 56 \\
\hline 3 & Ala87 & 356 & 25 & 244 & 625 \\
\hline 4 & Leu87 & 2 & 9 & 35 & 46 \\
\hline 5 & Ile 87 & 21 & 597 & 92 & 710 \\
\hline 6 & Val $87^{\mathrm{b}}$ & 641 & 351 & 218 & 1,210 \\
\hline 7 & Met87 & 11 & 33 & 36 & 81 \\
\hline 8 & Pro87 & - & - & - & - \\
\hline 9 & Trp87 & 15 & 6 & 8 & 29 \\
\hline \multicolumn{6}{|c|}{ Uncharged polar side chain } \\
\hline 10 & Ser87 & - & - & - & - \\
\hline 11 & Thr87 & 126 & 367 & 557 & 1,050 \\
\hline 12 & Asn87 & ND & ND & 35 & 35 \\
\hline 13 & Gln87 & 21 & ND & 119 & 140 \\
\hline 14 & Tyr87 & 625 & 288 & 337 & 1,250 \\
\hline 15 & Cys87 & 1 & ND & 4 & 5 \\
\hline \multicolumn{6}{|c|}{ Charged polar side chain } \\
\hline 16 & Lys87 & 3 & 9 & 13 & 25 \\
\hline 17 & Arg87 & 32 & ND & 33 & 65 \\
\hline 18 & His87 & 40 & ND & 135 & 175 \\
\hline 19 & Asp87 & - & - & - & - \\
\hline 20 & Glu87 & - & - & - & - \\
\hline 21 & Wild type (Phe87) & ND & ND & ND & ND \\
\hline
\end{tabular}

$15 \beta$-OH-T $15 \beta$-hydroxytestosterone, $16 \beta-O H-T 16 \beta$-hydroxytestosterone, $2 \beta$-OH-T $2 \beta$-hydroxytestosterone, $N D$ not detectable

${ }^{\text {a }}$ Specific activities observed with $0.5 \mathrm{mM}$ testosterone and $200 \mathrm{nM} \mathrm{P} 450$ BM3. The values represent averages of two measurements; variability was always less than $10 \%$

b CYP102A1 M11 containing R47L, E64G, F81I, F87V, E143G, L188Q, E267V, and G415S [22]

obtained with $15 \beta-\mathrm{OH}-\mathrm{T}$ as the major metabolite (50-55\%), and with $16 \beta-\mathrm{OH}-\mathrm{T}$ and $2 \beta-\mathrm{OH}-\mathrm{T}$ formed in approximately equal amounts (20-25\%). Compared with these mutants, the mutant containing Ala87 and Ile87 showed remarkable differences in regioselectivity of D-ring hydroxylation. The mutant containing Ile87 was the only mutant having high selectivity for $16 \beta$-hydroxylation, whereas the mutant containing Ala87 showed predominantly $15 \beta$-hydroxylation, in addition to significant $2 \beta$-hydroxylation at the A-ring.

Mutants containing Phe87 and Thr87, which had relatively high activity, showed $2 \beta-\mathrm{OH}-\mathrm{T}$ as the major metabolite, with lower amounts of $16 \beta-\mathrm{OH}-\mathrm{T}$ and the lowest amounts of $15 \beta-\mathrm{OH}-\mathrm{T}$. Similar results were obtained with the much less active mutants with residues Met87, Lys87, and Leu87. Mutants containing Cys87, His87, Gln87, and Asn87 also showed the highest preference for A-ring hydroxylation with $2 \beta-\mathrm{OH}-\mathrm{T}$ as the major metabolite. For three of these mutants, D-ring hydroxylation was only found at the $15 \beta$-position; for Asn87 no significant D-ring hydroxylation was observed.

\section{Discussion}

The role of the residue at position 87 has been investigated in many studies using wild-type CYP102A1 and mutants containing one or two other mutations (Table 1). These studies are hampered by the fact that only a limited number of substrates are accepted, such as medium-chain and longchain fatty acids and small terpenoid and aromatic substrates. Also, so far only a limited number of amino acid substitutions have been evaluated at position 87. By far most studies have been performed with F87A and to a lesser extent with F87V and F87L. When applied to mutant 9-10A, containing R47C, V78A, K94I, P142S, T175I, A184V, F205C, S226R, H236Q, E252G, R255S, A290V, and $\mathrm{L} 353 \mathrm{~V}$, addition of mutation of F87A resulted in high enantioselectivity in buspirone hydroxylation [16], showing that residue 87 also has an important role in more promiscuous mutants of CYP102A1. However, the effects of other amino acid substitutions were not reported. In the present study, the role of position 87 in controlling substrate and regioselectivity of drug-metabolizing mutant CYP102A1 M11 was evaluated by creation of mutants with all 20 natural amino acids at this position. Twelve of the amino acid substitutions had not been reported previously in any CYP102A1 variant. To characterize the catalytic properties of these novel mutants, nine different alkoxyresorufins and testosterone were used as probe substrates.

As shown in Tables 3 and 7, very significant different rates of product formation were found between the different mutants. In the case of alkoxyresorufins as the substrate, the mutant containing Phe87 only showed a very low O-dealkylation activity with longer-chain alkoxyresorufins starting from $n$-hexoxyresorufin, with activities similar to that obtained with wild-type CYP102A1, which also contains Phe87. The mutants with the small nonpolar amino acids Gly87, Ala87, Val87, and Ile87 all showed much higher O-dealkylation activities, with an optimal activity with $n$-pentoxyresorufin as the substrate (Table 3). As summarized in Table 1, replacement of the bulky Phe87 in wild-type CYP102A1 by these small amino acids also showed generally an increased activity toward non-fatty acid substrates. Furthermore, the fact that mutants containing Val87, Leu87, and Ile87 showed large differences in activity toward $n$-alkoxyresorufins, and strongly 
Fig. 3 Effect of amino acid at position 87 on regioselective hydroxylation of testosterone by CYP102A1 mutants. Bars represent the percentage of product relative to the total amount of products. Numbers below each bar represent the ratio of D-ring hydroxylation (sum of $15 \beta$-hydroxylation and $16 \beta$-hydroxylation) and

A-ring hydroxylation

(2$\beta$-hydroxylation)

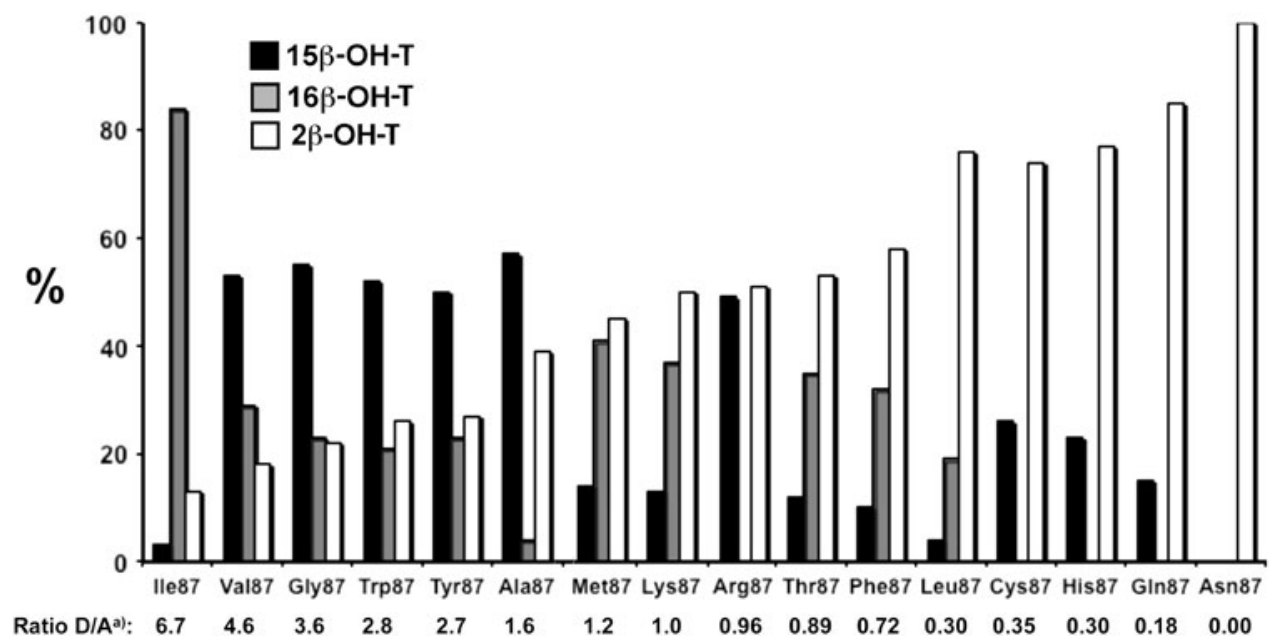

different regioselectivity in testosterone hydroxylation, demonstrates that even minor changes in amino acid properties of the residue at position 87 can have a large effect on catalytic properties.

It was proposed previously that replacement of the bulky Phe 87 by smaller nonpolar residues creates space for bulky substrates, allowing better positioning with respect to the activated oxygen species, and as a result higher activities and coupling efficiencies [8, 10]. To test whether coupling efficiencies were affected by amino acid 87 substitutions, the ratio of product formation to NADPH consumption was studied. As shown in Table 4, extremely high activities of substrate-induced NADPH consumption were found with all mutants and, unexpectedly, wild-type CYP102A1. For the most active enzymes, the specific activities of NADPH consumption were close to the high specific activities found with wild-type CYP102A1 and lauric acid and arachidonic acid as substrates [8, 9]. Because resorufin was the only product found, the coupling efficiency was always less than $1 \%$ for all productive enzymes (Table 5). The fact that $20 \mu \mathrm{M}$ substrate resulted in complete depletion of $200 \mu \mathrm{M}$ NADPH within 2-3 min indicates that NADPH consumption resulted from a catalytic process in which the substrate triggers NADPH consumption without being converted, such as uncoupling or redox cycling in which the substrate undergoes one-electron reduction followed by autoxidation by molecular oxygen. Uncoupling of P450 is still a poorly understood process, and is considered to result from premature release of iron-bound molecular oxygen before completion of the catalytic cycle, producing superoxide anion radical (one-electron reduction) or hydrogen peroxide (two-electron reduction; "peroxide shunt") or by reduction of the $[\mathrm{FeO}]^{3+}$ intermediate producing water (oxidase pathway) $[36,37]$. Factors which might determine the mode of uncoupling are active-site hydration, which might favor the peroxide shunt, and the position of the substrate in the active site and/or a large distance from the
$[\mathrm{FeO}]^{3+}$ intermediate to the substrate $[36,37]$. Because the mutants contain amino acids at position 87 with different polarities and size, different modes of uncoupling might underlie the high NADPH consumptions observed in the present study. An alternative mechanism which might explain alkoxyresorufin-induced NADPH reduction is reduction of alkoxyresorufin at the level of the reductase domain. Previously it was shown that rat liver microsomal NADPH-cytochrome $\mathrm{P} 450$ reductase was able to catalyze redox cycling of resorufin by one-electron reduction of the quinoneimine moiety [38]. However, the fact that ketoconazole was able to almost completely inhibit alkoxyresorufin-induced NADPH consumption by wild-type CYP102A1 and mutant Val87 does not support this alternative mechanism. Also, the fact that alkoxyresorufins produce type I binding spectra when titrated to CYP102A1 and CYP102A1 mutants (Table 6) indicates that these substrates bind with relatively high affinity to the substrate binding site of these enzymes. These results strongly suggest that alkoxyresorufins bind to CYP102A1 at the active site mainly in a nonproductive orientation. However, the mechanism by which alkoxyresorufins stimulated extremely high NADPH consumption in the position 87 mutants and wild-type CYP102A1 still remains to be elucidated.

Previously, several mutations of position 87 in wild-type CYP102A1 were shown to change regioselectivity and stereoselectivity of several reactions (Table 1). In this study, testosterone was used as the substrate to characterize the regioselectivity of the different mutants. It was found that all mutants tested were able to catalyze testosterone hydroxylation, although with widely different activities and with different regioselectivities (Table 6). Only three different metabolites were formed in significant amounts, as was shown previously in incubations with the triple-mutant of CYP102A1 containing mutations R47L, F87V, and L188Q [26]. Interestingly, the mutant containing Phe87 appeared to be a relatively active enzyme, whereas the 
wild-type CYP102A1, which also contains Phe87, was completely inactive. Structural identification of the metabolites by NMR experiments revealed that two of the metabolites result from hydroxylation of the D-ring, at positions $15 \beta$ and $16 \beta$; the third metabolite results from hydroxylation of the A-ring at position $2 \beta$. Available crystal structures of CYP102A1 indicate that its substrate binding site is a long hydrophobic channel, with the heme iron located at the bottom of this channel [6]. This might explain why only the protons of the A-ring and D-ring of testosterone might approach the reactive iron-oxo species close enough to become hydroxylated. As shown in Fig. 3, several mutants have a strong preference for D-ring hydroxylation, whereas others prefer hydroxylation of the A-ring. The mutant containing Ile87 catalyzes predominantly $16 \beta$-hydroxylation, whereas in the case of the closely related leucine amino acid testosterone hydroxylation takes place predominantly as $2 \beta$-hydroxylation. Why these relatively small changes in amino acid side chain have such a large effect on regioselectivity remains to be established however. Screening of over 200 microbial P450s [27] and genetic engineering of bacterial $\mathrm{P} 450$ s previously enabled several other P450s to be identified that can catalyze $2 \beta$-hydroxylation and $15 \beta$-hydroxylation of testosterone $[27,39]$. Although several enzymes were shown to catalyze $16 \alpha$-hydroxylation, so far no bacterial P450s have been reported that can catalyze $16 \beta$-hydroxylation of steroids. The present study shows that the CYP102A1 mutant containing Ile87 is the first mutant with high selectivity for $16 \beta$-hydroxylation.

As summarized in Table 1, by far most amino acid substitutions at position 87 which have been reported involved mutations of Phe87 to amino acids with small nonpolar side chains. Only two amino acids (Tyr and Ser) with uncharged polar side chains have been studied, whereas charged polar side chains have not been evaluated. Mutation F87Y, when applied to wild-type CYP102A1, resulted in an unproductive enzyme when long-chain fatty acids were used as the substrate $[8,9,17]$. The increased polarity caused by the hydroxyl group at the phenyl ring of Tyr87 was considered to restrict heme accessibility of the fatty acid substrates, and as a result causes full uncoupling [8]. In the present study the mutant containing Tyr87 appeared more active than that containing Phe 87 with both alkoxyresorufins and testosterone as the substrate. Although Ser87 was not evaluated because the CO difference spectrum only showed a P420 spectrum, the mutant containing Thr87 showed a P450 spectrum, and was one of the most active mutants with testosterone as the substrate (Table 7). The other uncharged and charged polar amino acids also showed enzyme activity, although this was generally low when compared with the enzyme activity of the nonpolar amino acids. However, the substrates used in the present study were all uncharged substrates. Therefore, it remains to be evaluated whether the mutants containing polar amino acids at position 87 will have higher affinity and activity with charged and polar substrates.

In conclusion, the results of this study show that, consistent with the results of studies performed with wild-type enzyme, the nature of the amino acid at position 87 has a strong effect on the activity and regioselectivity of drugmetabolizing mutants of CYP102A1. Several amino acid substitutions not previously evaluated were shown to be dependent on the substrates tested, active enzymes with different substrate and regioselectivity. Because of the wide substrate selectivity of CYP102A1 M11 when compared with wild-type CYP102A1, this panel of mutants will be useful as biocatalysts for metabolite production. Furthermore, these mutants might be valuable model proteins for mechanistic studies on the function of P450s in drug metabolism.

Acknowledgments This work was supported by grant D2-102-1 from the Dutch Top Institute Pharma.

Open Access This article is distributed under the terms of the Creative Commons Attribution Noncommercial License which permits any noncommercial use, distribution, and reproduction in any medium, provided the original author(s) and source are credited.

\section{References}

1. Munro AW, Leys DG, McLean KJ, Marshall KR, Ost TW, Daff S, Miles CS, Chapman SK, Lysek DA, Moser CC, Page CC, Dutton PL (2002) P450 BM3: the very model of a modern flavocytochrome. Trends Biochem Sci 27:250-257

2. Warman AJ, Roitel O, Neeli R, Girvan HM, Seward HE, Murray SA, McLean KJ, Joyce MG, Toogood H, Holt RA, Leys D, Scrutton NS, Munro AW (2005) Flavocytochrome P450 BM3: an update on structure and mechanism of a biotechnologically important enzyme. Biochem Soc Trans 33:747-753

3. Eiben S, Kaysser L, Maurer S, Kühnel K, Urlacher VB, Schmid RD (2006) Preparative use of isolated CYP102 monooxygenases-a critical appraisal. J Biotechnol 124:662-669

4. Sawayama AM, Chen MM, Kulanthaivel P, Kuo MS, Hemmerle H, Arnold FH (2009) A panel of cytochrome P450 BM3 variants to produce drug metabolites and diversify lead compounds. Chemistry 15:11723-11729

5. Van Vugt-Lussenburg BM, Stjernschantz E, Lastdrager J, Oostenbrink C, Vermeulen NPE, Commandeur JNM (2007) Identification of critical residues in novel drug metabolizing mutants of cytochrome P450 BM3 using random mutagenesis. J Med Chem 50:455-461

6. Li H, Poulos TL (1997) The structure of the cytochrome p450BM-3 haem domain complexed with the fatty acid substrate, palmitoleic acid. Nat Struct Biol 4:140-146

7. Oliver CF, Modi S, Sutcliffe MJ, Primrose WU, Lian LY, Roberts GC (1997) A single mutation in cytochrome P450 BM3 changes substrate orientation in a catalytic intermediate and the regiospecificity of hydroxylation. Biochemistry 36:1567-1572

8. Graham-Lorence S, Truan G, Peterson JA, Falck JR, Wei S, Helvig C, Capdevilla JH (1997) An active site substitution, F87V, 
converts cytochrome P450 BM-3 into a regio- and stereoselective (14S, 15R)-arachidonic acid epoxygenase. J Biol Chem 272:1127-1135

9. Noble MA, Miles CS, Chapman SK, Lysek DA, Mackay AC, Reid GA, Hanzlik RP, Munro AW (1999) Roles of key active-site residues in flavocytochrome P450 BM3. Biochem J 339:371-379

10. Carmichael AB, Wong L-L (2001) Protein engineering of Bacillus megaterium CYP102. The oxidation of polycyclic aromatic hydrocarbons. Eur J Biochem 268:3117-3125

11. Li Q-S, Ogawa J, Schmid RD, Shimizu S (2001) Residue size at position 87 of cytochrome P450 BM-3 determines its stereoselectivity in propylbenzene and 3-chlorostyrene oxidation. FEBS Lett 508:249-252

12. Li Q-S, Ogawa J, Schmid RD, Shimizu S (2001) Engineering cytochrome P450 BM-3 for oxidation of polycyclic aromatic hydrocarbons. Appl Environ Microbiol 67:5735-5739

13. Lussenburg BM, Babel LC, Vermeulen NPE, Commandeur JNM (2005) Evaluation of alkoxyresorufins as fluorescent substrates for cytochrome P450 BM3 and site-directed mutants. Anal Biochem 341:148-155

14. Sowden RJ, Yasmin S, Rees NH, Bell SG, Wong L (2005) Biotransformation of the sesquiterpene $(+)$-valencene by cytochrome P450cam and P450BM-3. Org Biomol Chem. 3:57-64

15. Sulistyaningdyah WT, Ogawa J, Li Q-S, Maeda C, Yano Y, Schmid RD, Shimizu S (2005) Hydroxylation activity of P450 BM-3 mutant F87V towards aromatic compounds and its application to the synthesis of hydroquinone derivatives from phenolic compounds. Appl Microbiol Biotechnol 67:556-562

16. Landwehr M, Hochrein L, Otey CR, Hasrayan A, Bäckvall J-E, Arnold FH (2006) Enantioselective alpha-hydroxylation of 2-arylacetic acid derivatives and buspirone catalyzed by engineered cytochrome P450 BM-3. J Am Chem Soc 128:6058-6059

17. Kitazume T, Haines DC, Estabrook RW, Chen B, Peterson JA (2007) Obligatory intermolecular electron-transfer from FAD to FMN in dimeric P450BM-3. Biochemistry 46:11892-11901

18. Chen CK, Shokhireva TK, Berry RE, Zhang H, Walker FA (2008) The effect of mutation of F87 on the properties of CYP102A1-CYP4C7 chimeras: altered regiospecificity and substrate selectivity. J Biol Inorg Chem 13:813-824

19. Dietrich M, Do TA, Schmid RD, Pleiss J, Urlacherm VB (2009) Altering the regioselectivity of the subterminal fatty acid hydroxylase P450 BM-3 towards gamma- and delta-positions. J Biotechnol 139:115-117

20. Kim DH, Ahn T, Jung HC, Pan JG, Yun CH (2009) Generation of the human metabolite piceatannol from the anticancer-preventive agent resveratrol by bacterial cytochrome P450 BM3. Drug Metab Dispos 37:932-936

21. Seifert A, Vomund S, Grohmann K, Kriening S, Urlacher VB, Laschat S, Pleiss J (2009) Rational design of a minimal and highly enriched CYP102A1 mutant library with improved regio-, stereo- and chemoselectivity. Chembiochem 10:853-861

22. Damsten MC, van Vugt-Lussenburg BM, Zeldenthuis $\mathrm{T}$, de Vlieger JS, Commandeur JNM, Vermeulen NPE (2008) Application of drug metabolising mutants of cytochrome P450 BM3 (CYP102A1) as biocatalysts for the generation of reactive metabolites. Chem Biol Interact 171:96-107

23. Burke MD, Thompson S, Weaver RJ, Wolf CR, Mayer RT (1994) Cytochrome P450 specificities of alkoxyresorufin O-dealkylation in human and rat liver. Biochem Pharmacol 48:923-936

24. Burke MD, Mayer RT (1983) Differential effects of phenobarbitone and 3-methylcholanthrene induction on the hepatic microsomal metabolism and cytochrome P-450-binding of phenoxazone and a homologous series of its $n$-alkyl ethers (alkoxyresorufins). Chem Biol Interact 45:243-258

25. Burke MD, Thompson S, Elcombe CR, Halpert J, Haaparanta T, Mayer RT (1983) Ethoxy-, pentoxy- and benzyloxyphenoxazones and homologues: a series of substrates to distinguish between different induced cytochromes P-450. Biochem Pharmacol 34:3337-3345

26. Van Vugt-Lussenburg BMA, Damsten MC, Maasdijk DM, Vermeulen NPE, Commandeur JNM (2006) Heterotropic and homotropic cooperativity by a drug-metabolising mutant of cytochrome P450 BM3. Biochem Biophys Res Commun 346:810-818

27. De Vlieger JS, Kolkman AJ, Ampt KA, Commandeur JNM, Vermeulen NPE, Kool J, Wijmenga SS, Niessen WM, Irth H, Honing M (2010) Determination and identification of estrogenic compounds generated with biosynthetic enzymes using hyphenated screening assays, high resolution mass spectrometry and offline NMR. J Chromatogr B Anal Technol Biomed Life Sci 878:667-674

28. Agematu H, Matsumoto N, Fujii Y, Kabumoto H, Doi S, Machida K, Ishikawa J, Arisawa A (2006) Hydroxylation of testosterone by bacterial cytochromes $\mathrm{P} 450$ using the Escherichia coli expression system. Biosci Biotechnol Biochem 70:307-311

29. Fernandes P, Cruz A, Angelova B, Pinheiro HM, Cabral JMS (2003) Microbial conversion of steroid compounds: recent developments. Enzyme Microb Technol 32:688-705

30. Omura T, Sato R (1964) The carbon monoxide-binding pigment of liver microsomes. II. Solubilization, purification and properties. J Biol Chem 239:2379-2385

31. Wang D, Zhang M (2007) Rapid quantitation of testosterone hydroxyl metabolites by ultra-performance liquid chromatography and mass spectrometry. J Chromatogr B 855:290-294

32. Reinen J, Ferman S, Vottero E, Vermeulen NPE, Commandeur JNM (2011) Application of a fluorescence-based continuous-flow bioassay to screen for diversity of cytochrome P450 BM3 mutant libraries. J Biomol Screen 16:239-250

33. Perera R, Sono M, Sigman JA, Pfister TD, Lu Y, Dawson JH (2003) Neutral thiol as a proximal ligand to ferrous heme iron: implications for heme proteins that lose cysteine thiolate ligation on reduction. Proc Natl Acad Sci USA 100:3641-3646

34. Rea V, Kolkman AJ, Vottero E, Stronks E, Ampt KAM, Vermeulen NPE, Wijmenga SS, Commandeur JNM Restriction of active site volume of cytochrome P450 BM3 mutants improves regioselectivity of steroid hydroxylation as rationalised by spin relaxation NMR studies (submitted)

35. Jacobsen NE, Köver KE, Murataliev MB, Feyereisen R, Walker FA (2006) Structure and stereochemistry of products of hydroxylation of human steroid hormones by a housefly cytochrome P450 (CYP6A1). Magn Reson Chem 44:467-474

36. Loida PJ, Sligar SG (1993) Molecular recognition in cytochrome P-450: mechanism for the control of uncoupling reactions. Biochemistry 32:11530-11538

37. Yeom H, Sligar SG (1997) Oxygen activation by cytchrome

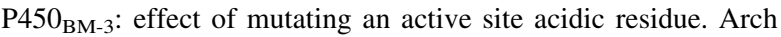
Biochem Biophys 337:209-216

38. Dutton DR, Reed GA, Parkinson A (1989) Redox cycling of resorufin catalyzed by rat liver microsomal NADPH-cytochrome P450 reductase. Arch Biochem Biophys 268:605-616

39. Virus C, Lisurek M, Hanneman F, Bernhardt R (2006) Function and engineering of the 15 $\beta$-hydroxylase CYP106A2. Biochem Soc Trans 34:1215-1218 